\title{
Low temperature silicon dioxide by thermal atomic layer deposition: Investigation of material properties
}

\author{
D. Hiller, ${ }^{1,2, a)}$ R. Zierold, ${ }^{3}$ J. Bachmann, ${ }^{3,2}$ M. Alexe, ${ }^{2}$ Y. Yang, ${ }_{7}^{1,2}$ J. W. Gerlach, ${ }^{4}$ \\ A. Stesmans, ${ }^{5}$ M. Jivanescu, ${ }^{5}$ U. Müller, ${ }^{6}$ J. Vogt, ${ }^{7}$ H. Hilmer, ${ }^{7}$ P. Löper, ${ }^{8}$ M. Künle, ${ }^{8}$ \\ F. Munnik, ${ }^{9}$ K. Nielsch, ${ }^{3}$ and M. Zacharias ${ }^{1}$ \\ ${ }^{1}$ Faculty of Engineering, IMTEK, Albert-Ludwigs-University Freiburg, Georges-Köhler-Allee 103, \\ 79110 Freiburg, Germany \\ ${ }^{2}$ Max Planck Institute of Microstructure Physics, Weinberg 2, 06120 Halle, Germany \\ ${ }^{3}$ Institute of Applied Physics, Hamburg University, Jungiusstrasse 11, 20355 Hamburg, Germany \\ ${ }^{4}$ Leibniz Institute of Surface Modification (IOM), Permoserstrasse 15, 04318 Leipzig, Germany \\ ${ }^{5}$ Department of Physics, University of Leuven, Celestijnenlaan 200D, 3001 Leuven, Belgium \\ ${ }^{6}$ Swiss Federal Laboratories for Materials Testing and Research (EMPA), Überlandstrasse 129, \\ CH-8600 Dübendorf, Switzerland \\ ${ }^{7}$ Faculty of Physics and Earth Sciences, University of Leipzig, Linnéstrasse 5, 04103 Leipzig, Germany \\ ${ }^{8}$ Fraunhofer ISE, Heidenhofstrasse 2, 79110 Freiburg, Germany \\ ${ }^{9}$ Forschungszentrum Dresden-Rossendorf e.V., Bautzner Landstrasse 400, 01328 Dresden, Germany
}

(Received 17 December 2009; accepted 25 January 2010; published online 29 March 2010)

\begin{abstract}
$\mathrm{SiO}_{2}$ is the most widely used dielectric material but its growth or deposition involves high thermal budgets or suffers from shadowing effects. The low-temperature method presented here $\left(150{ }^{\circ} \mathrm{C}\right)$ for the preparation of $\mathrm{SiO}_{2}$ by thermal atomic layer deposition (ALD) provides perfect uniformity and surface coverage even into nanoscale pores, which may well suit recent demands in nanoelectronics and nanotechnology. The ALD reaction based on 3-aminopropyltriethoxysilane, water, and ozone provides outstanding $\mathrm{SiO}_{2}$ quality and is free of catalysts or corrosive by-products. A variety of optical, structural, and electrical properties are investigated by means of infrared spectroscopy, UV-Vis spectroscopy, secondary ion mass spectrometry, capacitance-voltage and current-voltage measurements, electron spin resonance, Rutherford backscattering, elastic recoil detection analysis, atomic force microscopy, and variable angle spectroscopic ellipsometry. Many features, such as the optical constants $(\mathrm{n}, \mathrm{k})$ and optical transmission and surface roughness $(1.5 \AA)$, are found to be similar to thermal oxide quality. Rapid thermal annealing (RTA) at $1000{ }^{\circ} \mathrm{C}$ is demonstrated to significantly improve certain properties, in particular by reducing the etch rate in hydrofluoric acid, oxide charges, and interface defects. Besides a small amount of $\mathrm{OH}$ groups and a few atomic per mille of nitrogen in the oxide remaining from the growth and curable by RTA no impurities could be traced. Altogether, the data point to a first reliable low temperature ALD-growth process for silicon dioxide. (C) 2010 American Institute of Physics. [doi:10.1063/1.3327430]
\end{abstract}

\section{INTRODUCTION}

Silicon dioxide is the most widely used dielectric material for optical and electronic applications. However, conventional deposition techniques for $\mathrm{SiO}_{2}$ (e.g., chemical vapor deposition, sputtering, electron beam evaporation, etc.) have two main disadvantages: the necessity of a high growth temperature and the shadowing effect, causing a poor surface coverage in the case of structured substrates. Atomic layer deposition (ALD) provides a technique to circumvent these problems. ${ }^{1}$ To date, atomic layer deposited $\mathrm{SiO}_{2}$ has been rarely processed and had involved either high temperatures $\left(>300{ }^{\circ} \mathrm{C}\right),{ }^{2}$ catalysts, ${ }^{3,4}$ or corrosive by-products. ${ }^{5}$ Besides these thermal ALD approaches, one report on plasmaenhanced ALD was published, however, with rather insufficient material purity (several atom percent of carbon and nitrogen contamination). ${ }^{6}$ Recently, the deposition of $\mathrm{SiO}_{2}$ has been reported by thermal ALD using a self-catalytic reaction based on 3-aminopropyltriethoxysilane (APTES), wa-

${ }^{a)}$ Electronic mail: daniel.hiller@imtek.uni-freiburg.de. ter, and ozone as precursors. ${ }^{7}$ It was shown that a high degree of thickness control and perfect surface coverage even into nanoscale pores can be achieved at low growth temperatures $\left(120-200{ }^{\circ} \mathrm{C}\right)$.

An ultrathin layer of $\mathrm{SiO}_{2}$ is of advantage as interlayer between the Si substrate and high- $\kappa$ dielectrics (with $\kappa$ as the dielectric constant). ${ }^{8}$ It would enable one to establish the standard high $\mathrm{Si} / \mathrm{SiO}_{2}$ interface quality, yet its thickness should be limited to the bare minimum to meet the low equivalent-oxide-thickness requirement. $\mathrm{SiO}_{2}$ also possesses the possibility to prevent chemical reactions of the high- $\kappa$ material with the silicon substrate. ${ }^{9}$ ALD is the favorite deposition technique for high- $\kappa$ materials but an incubation period for the growth of the initial layers can result in a delay of several ALD cycles before the onset of linear growth. ${ }^{10}$ Chemical oxide is the most suitable surface for linear deposition due to its high concentration of $\mathrm{OH}$ groups, as demonstrated by studies on the initial growth of hafnium oxide on silicon substrates with various pretreatments, while ultrathin thermal oxide and $\mathrm{H}$-terminated silicon yielded a much worse performance. ${ }^{11}$ Since the ALD-grown oxide presented 
here is terminated by $\mathrm{OH}$ groups, it might subsequently enable linear ALD growth of high- $\kappa$ materials from the very beginning but with a higher degree of thickness control in the low nanometer range. Therefore, an in situ gate stack deposition of $\mathrm{SiO}_{2}$ and high-k material could be realized with the help of ALD-SiO 2 . In addition, the increasing interest in three-dimensional (3D) transistor structures (e.g., nanowire or FinFETs) requires ultrathin $\mathrm{SiO}_{2}$ as gate insulator, diffusion barrier, or sacrificial layer covering 3D nanostructures homogeneously during processing. Hence, new and superior $\mathrm{SiO}_{2}$ deposition techniques are required since thermal oxidation is only applicable to planar silicon and cannot form homogeneous and uniform layers on convex and concave curvatures of structured silicon due to stress. ${ }^{12}$ The investigation of the electronic properties of $\mathrm{SiO}_{2}$ prepared by ALD is mandatory for its future use in $3 \mathrm{D}$ nanoelectronics. Furthermore, various applications in nanobiotechnology also favor $\mathrm{SiO}_{2}$ due to its biocompatibility and chemical stability. ${ }^{13-15}$ Recently, the applicability of $\mathrm{ALD}-\mathrm{SiO}_{2}$ as a protective and inert material was demonstrated by deposition of a $\mathrm{SiO}_{2} / \mathrm{Fe}_{2} \mathrm{O}_{3} / \mathrm{SiO}_{2}$ layer stack into anodic aluminum oxide (AAO) templates and subsequent thermal reduction in hydrogen to ferrimagnetic $\mathrm{Fe}_{3} \mathrm{O}_{4}{ }^{16}$ In Ref. 17 the improvement by $\mathrm{ALD}-\mathrm{SiO}_{2}$ coverage of AAO-based $\mathrm{pH}$ sensors has been demonstrated.

In this publication we present detailed material properties of this novel low temperature $\mathrm{ALD}-\mathrm{SiO}_{2}$ layers obtained by extensive characterization using Fourier transform infrared spectroscopy (FTIR), UV-Vis spectroscopy, photoluminescence (PL), time-of-flight secondary ion mass spectrometry (TOF-SIMS), capacitance-voltage (CV) and currentvoltage measurements (IV), electron spin resonance (ESR), Rutherford backscattering spectrometry (RBS), elastic recoil detection analysis (ERDA), transmission electron microscopy (TEM), atomic force microscopy (AFM), variable angle spectroscopic ellipsometry (VASE) to determine optical constants, and laser ellipsometry for wet and dry chemical etch rates. Besides the quality achieved already after deposition (labeled as-prepared) we will evidence how rapid thermal annealing (RTA) can still improve material properties significantly.

\section{EXPERIMENTAL DETAILS}

The ALD process used here involves APTES, water, and ozone as precursors. The APTES precursor with a purity of 99\% was purchased from Sigma-Aldrich. The substrate temperature for all samples was $150{ }^{\circ} \mathrm{C}$. Details of the deposition process were published before. ${ }^{7}$ To account for various measurement techniques used here a variety of layer thicknesses resulting from 200 to 1500 ALD cycles were deposited onto different substrates such as $\mathrm{n}$ - and p-type silicon and quartz glass. Details are described in Table I. All substrates were thoroughly RCA cleaned prior to ALD of $\mathrm{SiO}_{2}$. The average growth per cycle was determined to be $0.85 \AA$. RTA was carried out in a JETFIRST $200 \mathrm{C}$ rapid thermal processor (RTP) from Jipelec at $1000{ }^{\circ} \mathrm{C}$ for 1 min under $\mathrm{N}_{2}$ atmosphere with ramp rates of about $100 \mathrm{~K} / \mathrm{s}$.

FTIR measurements were carried out with a Bruker
TABLE I. Overview of the ALD-SiO ${ }_{2}$ samples and substrates used for the different measurements presented in this study. The growth rate is about $0.85 \AA$ per cycle, hence the layer thicknesses were between approximately 20 and $130 \mathrm{~nm}$.

\begin{tabular}{lcc}
\hline \hline Measurement technique & Substrate & No. of ALD cycles \\
\hline FTIR & FZ-Si & 1000 \\
UV-Vis spectroscopy & Quartz glass & 1500 \\
SIMS, CV, TEM & n-Si & 200 \\
ESR, AFM, ERDA & p-Si & 1000 \\
IV & Cr on quartz glass & 500 \\
RBS, VASE & n-Si & 1000 \\
\hline \hline
\end{tabular}

IFS113V spectrometer from 400 to $4000 \mathrm{~cm}^{-1}$ with a resolution of $6 \mathrm{~cm}^{-1}$. UV-Vis transmission and reflection were measured in a Varian Cary-500i in the wavelength range from 250 to $2500 \mathrm{~nm}$ in steps of $1 \mathrm{~nm}$ using an integrating sphere. PL was measured with a single grating monochromator, $\mathrm{LN}_{2}$-cooled charge coupled device, and a $\mathrm{HeCd}$ laser (3.8 eV line) as excitation source. A TOF-SIMS (ION-TOF $\mathrm{GmbH}$ ) was used to investigate elemental composition and depth profile of the $\mathrm{SiO}_{2}$ layer. The measurements were performed using a $\mathrm{Cs}^{+}$ion sputter source operated at $0.5 \mathrm{keV}$ and $30 \mathrm{nA}$. The analysis was carried out in negative polarity using a pulsed $\mathrm{Ga}^{+}$ion beam at $15 \mathrm{keV}$ and $1 \mathrm{pA}$. An electron flood gun was used to compensate for sample charging. High-frequency (1 MHz) capacitance-voltage $(\mathrm{C}-\mathrm{V})$ and conductance-voltage (G-V) curves were measured using a HP4194A impedance analyzer. Current-voltage (I-V) measurements were carried out using a Keithley 6517 electrometer. Investigation of paramagnetic defects was performed using conventional cw locally constructed K-band $(\sim 20.5 \mathrm{GHz})$ ESR spectrometer driven in the adiabatic absorption mode and operated in the $4.2-300 \mathrm{~K}$ temperature range. All samples were investigated before and after extended irradiation by vacuum UV photons $(\mathrm{h} \nu \sim 10 \mathrm{eV})$ using a $\mathrm{Kr}$ resonant-discharge lamp equipped with a $\mathrm{MgF}_{2}$ window (flux $\sim 10^{15} \mathrm{~cm}^{-2} \mathrm{~s}^{-1}$ ) in order to maximally activate the defects. RBS was measured with $2 \mathrm{MeV} \mathrm{He}^{+}$projectiles under grazing incidence $\left(76^{\circ}\right)$ and a detection angle of $170^{\circ}$. The measurements were modeled by RUMP (RBS analysis package). ERDA was carried out using $35 \mathrm{MeV}^{35} \mathrm{Cl}^{7+}$ projectiles from a $5 \mathrm{MV}$ tandem accelerator. The scattering angle was $31^{\circ}$, the angle between beam and sample normal $75^{\circ}$. Recoiled target ions were detected by a Braggionization chamber. Only the hydrogen ions were detected separately under $38^{\circ}$ by a surface barrier detector with an $18 \mu \mathrm{m}$ Al-foil entrance window. WINDF was used to simulate the measurements. ${ }^{18}$ A TEM cross section micrograph was obtained with a JEM-1010 operated at $100 \mathrm{kV}$. Surface roughness was measured under ambient conditions on a MobileS AFM from Nanosurf with the $10 \mu \mathrm{m}$ scan head. Images were acquired in the noncontact mode (phase contrast operation mode) using a SuperSharpSilicon ${ }^{\mathrm{TM}}$ (SSS-NCLR) tip from Nanosensors. $1 \times 1 \mu \mathrm{m}^{2}$ images with 512 $\times 512$ pixel resolution were measured on an area with no larger dust particles and a linear line fit background subtraction was applied line by line prior to the roughness calculation. A spectral ellipsometer from J. A. Woollam Co., Inc. 


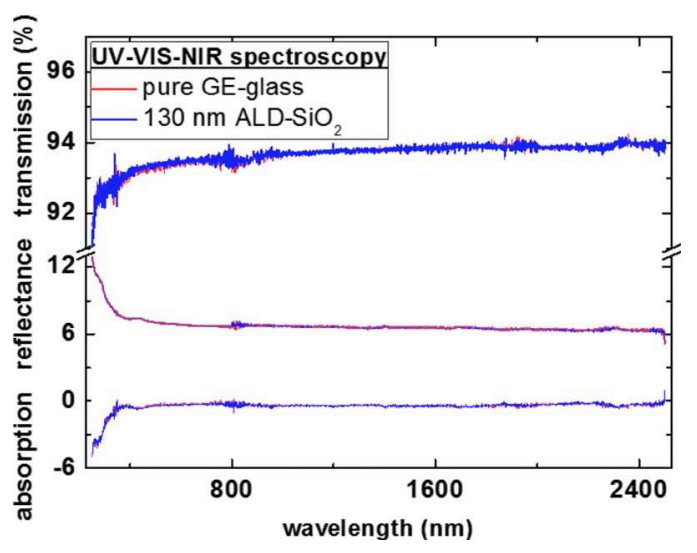

FIG. 1. (Color online) UV-Vis-NIR spectra of a $130 \mathrm{~nm}$ thick ALD-SiO film on quartz substrate. No measurable difference appears between the ALD-coated sample and the pure quartz, indicating no absorption of the ALD-SiO ${ }_{2}$ over the whole spectral range investigated.

was utilized for VASE measurements at $60^{\circ}$ and $70^{\circ}$ from 1.2 to $4.5 \mathrm{eV}$ in steps of $20 \mathrm{meV}$.

\section{RESULTS AND DISCUSSION}

\section{A. Optical properties}

Quartz glass, the amorphous form of bulk silicon dioxide, is the most prominent material for optical lenses, mirrors, and devices. Due to the high band gap of approximately $9 \mathrm{eV} \mathrm{SiO}_{2}$ has an excellent transmission behavior over a wide spectral range. Furthermore, it is possible to produce glass with a very high degree of purity to avoid luminescence centers such as alkali metals. Optical spectroscopy was performed from $250 \mathrm{~nm}$ (UV) to $2500 \mathrm{~nm}$ (NIR) to determine the transmission $(\mathrm{T})$ and reflectance $(\mathrm{R})$ behavior of $\mathrm{ALD}-\mathrm{SiO}_{2}$. The absorption $\mathrm{A}$ was calculated by $\mathrm{A}=1-\mathrm{R}$ $-\mathrm{T}$. The films were deposited onto $2 \mathrm{~mm}$ thick quartz glass substrates (GE-214) with 1500 ALD cycles, resulting in a layer thickness of about $130 \mathrm{~nm}$. The results are shown in Fig. 1. Over the whole spectral range there is no significant difference in either transmission or reflectance between the ALD-coated and the virgin GE glass. Please note that the negative absorption in the UV range originates from an artifact of the white standard used to calibrate the spectrometer. Thus, the evidence that $\mathrm{ALD}-\mathrm{SiO}_{2}$ shows outstanding optical properties identical to that of quartz glass is not affected.

PL was performed using $90 \mathrm{~nm}$ thick $\mathrm{ALD}-\mathrm{SiO}_{2}$ layers on silicon substrate since several possible luminescence centers are known in silicon dioxide, e.g., nonbridging oxygen hole centers at around $2 \mathrm{eV}$ and self-trapped excitons (2.6$2.8 \mathrm{eV}){ }^{19}$ Another typical $\mathrm{SiO}_{2}$ related defect is the $\mathrm{E}^{\prime}$-center; however, since its luminescence energy is 4.3-4.6 $\mathrm{eV}$ we cannot excite it with the $3.8 \mathrm{eV}$ line of the $\mathrm{HeCd}$ laser used in this setup. The presence of $E^{\prime}$ centers will be addressed by ESR. The PL measurements show no luminescence for $\mathrm{ALD}-\mathrm{SiO}_{2}$ in the as-prepared state. Thus, the quartz glass-like optical quality of as-prepared $\mathrm{ALD}-\mathrm{SiO}_{2}$ is confirmed.

Ellipsometry provides for ALD a well suited technique to measure in situ or ex situ film thickness and properties. In this study we present VASE data from $\mathrm{ALD}-\mathrm{SiO}_{2}$ films

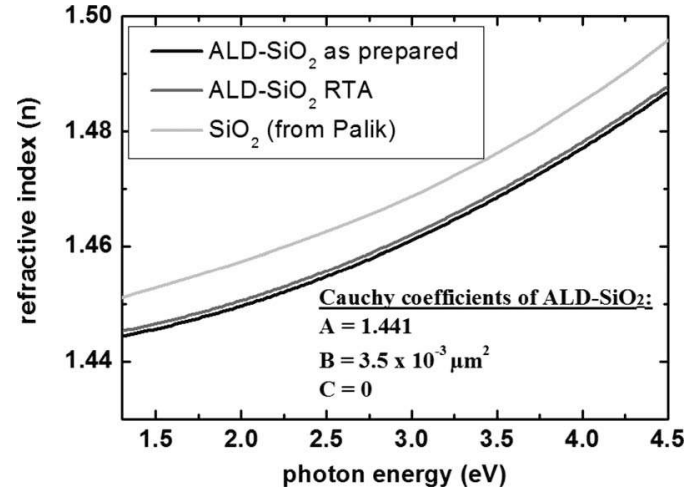

FIG. 2. Refractive index $n$ modeled by a Cauchy approximation from variable angle spectral ellipsometry measurements. The refractive index of asprepared and RTP-annealed $\mathrm{ALD}-\mathrm{SiO}_{2}$ is virtually identical. $\mathrm{SiO}_{2}$-data from the literature (Refs. 20 and 21) reveal an offset of only about $0.5 \%$. The modeled Cauchy parameters for $\mathrm{ALD}-\mathrm{SiO}_{2}$ are given in the figure.

grown by 1000 cycles on silicon wafers. The measured ellipsometric angles $\Psi$ and $\Delta$ were modeled by means of layer stack analysis where the dielectric functions of silicon oxide were obtained numerically to get the optical constants $n$ (refractive index) and $\mathrm{k}$ (extinction coefficient) as well as the layer thickness. In the model only the silicon substrate and the oxide layer were considered. A contribution of a surface roughness layer to the model was found to be negligible (see AFM section). Since the extinction coefficient $\mathrm{k}$ is almost zero over the whole spectral range we can use Cauchy's equation $\mathrm{n}(\lambda)=\mathrm{A}+\mathrm{B} / \lambda^{2}+\mathrm{C} / \lambda^{4}$ to model the refractive index (Fig. 2). The Cauchy coefficients of the fit of as-prepared ALD-SiO ${ }_{2}$ are also given in Fig. 2. At first sight it is evident that no significant differences exist between $\mathrm{ALD}-\mathrm{SiO}_{2}$ and data known from the literature. ${ }^{20,21}$ The almost constant offset in the refractive indices between the ALD and the thermal oxide is only about $0.5 \%$. A dry thermal oxide was measured as well and its data were found to be similar to the values tabulated in Ref. 20 (data not shown here). Furthermore, asprepared state and RTP-annealed sample show almost an identical optical behavior. Therefore, in terms of optical properties we can hardly distinguish between quartz glass or thermal oxide and our ALD-grown silicon oxide. The modeled thickness of the as-prepared sample was $86.6 \mathrm{~nm}$, corresponding to a growth per cycle of $0.85 \AA$ when $2 \mathrm{~nm}$ chemical oxide from the RCA cleaning procedure is taken into account. However, the annealed sample could be modeled by a thickness of only $78.4 \mathrm{~nm}$, unveiling a material compaction of $10 \%$ due to the $1000{ }^{\circ} \mathrm{C}$-RTA step.

\section{B. Structural and chemical properties}

In order to obtain further insight into the structural and chemical properties of $\mathrm{ALD}-\mathrm{SiO}_{2}$ we performed various measurements. First, the question of chemical stability and etch rates was investigated by laser ellipsometry measurements $(633 \mathrm{~nm})$ before and after various treatments. The asprepared material was subjected to RCA-1 $\left(\mathrm{NH}_{4} \mathrm{OH}+\mathrm{H}_{2} \mathrm{O}_{2}\right.$ $+\mathrm{H}_{2} \mathrm{O}$ at $\left.75^{\circ} \mathrm{C}\right)$, RCA-2 $\left(\mathrm{HCl}+\mathrm{H}_{2} \mathrm{O}_{2}+\mathrm{H}_{2} \mathrm{O}\right.$ at $\left.75^{\circ} \mathrm{C}\right)$, and piranha solution $\left(\mathrm{H}_{2} \mathrm{SO}_{4}+\mathrm{H}_{2} \mathrm{O}_{2}\right.$ at $\left.75^{\circ} \mathrm{C}\right)$, respectively, for 


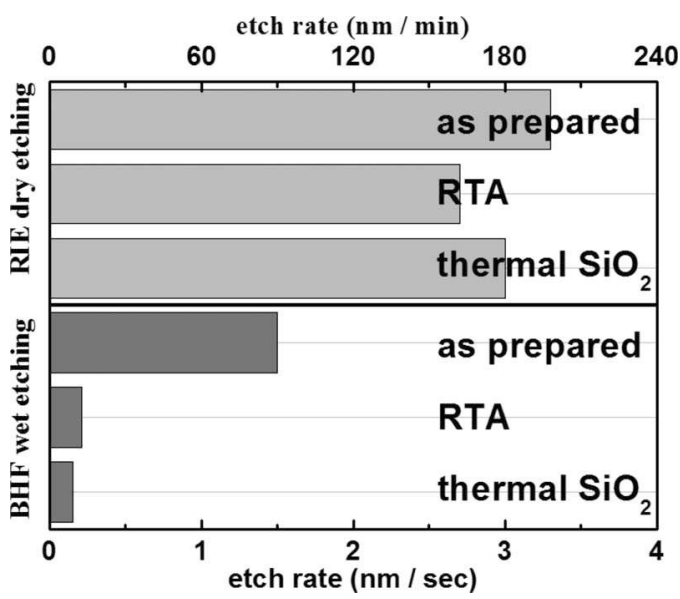

FIG. 3. Comparison of ALD-SiO ${ }_{2}$ etch rates measured by laser ellipsometry. The upper part shows the almost identical etch rates of ALD-SiO${ }_{2}$ and thermal oxide achieved by RIE. The lower part indicates a similar BHF acid etch rate for both RTP-annealed $\mathrm{ALD}-\mathrm{SiO}_{2}$ and dry thermal oxide. In the as-prepared state the ALD material is wet etched seven times faster, demonstrating the improvement by RTA.

10 min each. No thickness decrease could be measured indicating complete material stability against these common cleaning solutions.

Buffered hydrofluoric (BHF) acid diluted 1:12 with deionized water at room temperature was used as etchant for the ALD-SiO ${ }_{2}$ samples (as-prepared and after RTA) and a dry thermal oxide as reference. The average etch rates determined from six different etch times are presented in the lower part of Fig. 3. In the as-prepared state of $\mathrm{ALD}-\mathrm{SiO}_{2}$ a $\mathrm{BHF}$-etch rate of $1.5 \mathrm{~nm} / \mathrm{s}$ was measured; however, after RTA the etch rate is seven times lower $(0.2 \mathrm{~nm} / \mathrm{s})$. This value almost reaches that of dry thermal oxide $(0.15 \mathrm{~nm} / \mathrm{s})$. Hence substantial improvements in the material structure were induced by RTA at $1000{ }^{\circ} \mathrm{C}$. Since wet etch rates are typically accelerated by a loose material composition or pin holes, this result is in good agreement with the material densification of $10 \%$ measured by VASE. However, pin holes do not play a role in this context, as has been confirmed by AFM measurements (see AFM section and Fig. 8). Therefore, the variation in etch properties of our material upon RTA may have a chemical origin: $\mathrm{OH}$ groups present in the as-prepared material may assist in the heterolysis of $\mathrm{HF}$, thereby accelerating the etch rate of $\mathrm{OH}$ containing $\mathrm{SiO}_{2}$. In contrast to $\mathrm{HF}$ etching, dry etching by reactive ion etching (RIE) is most efficient if the material purity is high. In this work a RIE etcher (Surface Technology Systems STS) was used with a standard oxide recipe based on $\mathrm{CF}_{4}, \mathrm{CHF}_{3}$, and Ar chemistry. It was found that dry thermal oxide is etched with that recipe at rate of $3 \mathrm{~nm} / \mathrm{s}$ while, e.g., sheet glass wafers (i.e., impure silica) could be etched at a rate of only $1 \mathrm{~nm} / \mathrm{s}$. However, the ALD-SiO 2 was etched at a rate of 3.3 and $2.7 \mathrm{~nm} / \mathrm{s}$ (asprepared and RTA, respectively) indicating within measurement uncertainties similar RIE dry etch rates as thermal oxide.

FTIR was measured on float zone silicon (FZ-Si) substrates covered by 1000 ALD cycles of $\mathrm{SiO}_{2}$. Again, a dry thermal oxide of equal thickness was used as a reference. The FTIR spectra shown in Fig. 4 are baseline corrected and

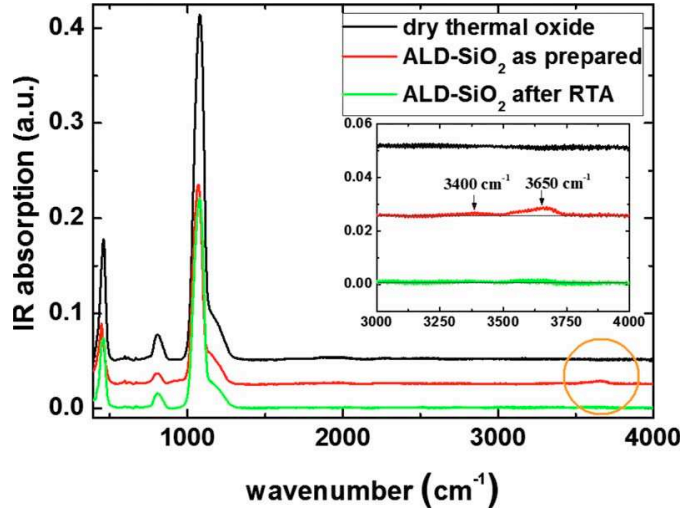

FIG. 4. (Color online) FTIR spectra of $\mathrm{ALD}_{-} \mathrm{SiO}_{2}$ (as-prepared and rapid thermal annealed) and dry thermal oxide. Besides the $\mathrm{Si}-\mathrm{O}$ related bonds only the as-prepared sample (red curve) shows a small peak around $3650 \mathrm{~cm}^{-1}$ (magnified in the inset) corresponding to the $\mathrm{Si}-\mathrm{O}-\mathrm{H}$ stretching mode. The elimination of the $\mathrm{OH}$ groups by RTA is demonstrated by the green curve.

the contribution from the Si substrate is subtracted. First of all, three prominent peaks are present for all samples: the $\mathrm{Si}-\mathrm{O}-\mathrm{Si}$ out-of-plane rocking mode $\left(460 \mathrm{~cm}^{-1}\right)$, the $\mathrm{Si}-$ $\mathrm{O}-\mathrm{Si}$ bending mode $\left(810 \mathrm{~cm}^{-1}\right)$, and the $\mathrm{Si}-\mathrm{O}-\mathrm{Si}$ stretching mode $\left(1075 \mathrm{~cm}^{-1}\right){ }^{22}$ In addition, only the as-prepared sample reveals a weak peak at $3650 \mathrm{~cm}^{-1}$ corresponding to the $\mathrm{Si}-\mathrm{O}-\mathrm{H}$ stretching mode. For better visibility the respective spectral region is magnified in the inset of Fig. 4. The baseline drawn in the inset for all three measurements is merely a guide for the eye. An extremely weak peak is also visible at $3400 \mathrm{~cm}^{-1}$ which could be the $\mathrm{H}-\mathrm{O}-\mathrm{H}$ stretching mode. In contrast, the $\mathrm{Si}-\mathrm{O}-\mathrm{H}-$ related peak at $3650 \mathrm{~cm}^{-1}$ is a clear evidence of the incorporation of $\mathrm{OH}$ groups into the $\mathrm{SiO}_{2}$ material during the ALD growth. Interestingly, it vanishes after RTP annealing which results in a FTIR spectrum identical to that of dry thermal oxide. Besides the OH-related signal no other signals such as $\mathrm{Si}-\mathrm{H}-, \mathrm{N}-\mathrm{H}-, \mathrm{N}-\mathrm{O}-$, or $\mathrm{Si}-$ $\mathrm{N}$-related modes could be evidenced by FTIR indicating no significant impurity incorporation from the APTES precursor.

The TOF-SIMS depth profiles of selected ions $\left({ }^{1} \mathrm{H}^{-},{ }^{28} \mathrm{Si}^{14} \mathrm{~N}^{-},{ }^{28} \mathrm{Si}_{3}{ }^{-}\right)$from the ALD-SiO 2 sample grown by 200 ALD cycles $(\sim 20 \mathrm{~nm})$ on silicon substrate and a dry thermal oxide of similar thickness grown by rapid thermal oxidation (RTO) are presented in Fig. 5. All signals have been normalized to the $\mathrm{Si}_{3}{ }^{-}$signal in bulk silicon. Besides the signals shown and other $\mathrm{Si}-\mathrm{O}$ compounds no other impurity masses were detected. Four regions of the depth profile can be distinguished: the sample surface with the usual superficial contaminations (hydrocarbons, water, etc.), the $\mathrm{SiO}_{2}$ layer, the interface, and the silicon substrate. A similar ${ }^{12} \mathrm{C}^{-}$signal of around 100 counts could be measured for all three samples in the oxide layers and in the substrate (not shown in Fig. 5). Only surface and interface exhibit a little higher carbon signal intensity. Therefore we can rule out significant carbon residues from the APTES precursor in the ALD silicon oxide. We used the $\mathrm{Si}_{3}{ }^{-}$signal to determine the interface since silicon atoms bound to more than one silicon atom $\left(\mathrm{Si}_{\mathrm{n}}, \mathrm{n}>2\right)$ are only present in the substrate, i.e., in contrast to the situation in the $\mathrm{SiO}_{2}$ layer. ${ }^{23}$ Notably, we ob- 


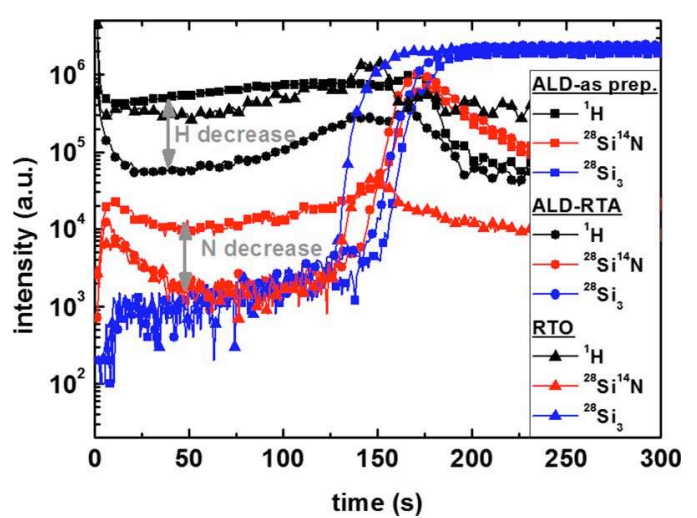

FIG. 5. (Color online) Comparison of TOF-SIMS depth profiles of selected ions $\left({ }^{1} \mathrm{H}^{-},{ }^{28} \mathrm{Si}^{14} \mathrm{~N}^{-},{ }^{28} \mathrm{Si}_{3}{ }^{-}\right)$for ALD-SiO $\mathrm{S}_{2}$ as-prepared $(\boldsymbol{\square})$, after RTA $(\bullet)$, and a rapid thermal oxide (RTO, symbol: $\mathbf{\Delta}$ ). The increase in the $\mathrm{Si}_{3}$ signal (blue) indicates the layer-substrate interface. The as-prepared ALD oxide contains a small amount of hydrogen and nitrogen which can be decreased to thermal oxide values by RTA. Besides, no other impurities such as carbon could be detected.

serve in the films a constant increase in the $\mathrm{H}^{-}$and $\mathrm{Si}_{3}{ }^{-}$ signals toward the interface which cannot be attributed to a material inherent property, as has been checked in comparison to the homogeneous thermal oxide where similar effects were obtained, i.e., this might be a measurement artifact. The most obvious difference between the as-prepared sample (ם) and the RTA sample (-) is the intensity of the hydrogen signal, as shown in Fig. 5. We observe a reduction in one order of magnitude by RTA while the ${ }^{1} \mathrm{H}$-level in the substrate of these two samples is identical. Furthermore, we only have a slightly higher ${ }^{1} \mathrm{H}$-signal in the middle of the RTA sample (@) compared with the Si substrate indicating a very low $\mathrm{H}$ content. In contrast to this, the $\mathrm{H}$ level in the asprepared sample ( $\boldsymbol{\square})$ is one order of magnitude higher compared with its substrate. Comparison to the thermal oxide (ム) shows a constant albeit higher ${ }^{1} \mathrm{H}$-level in the layer and the substrate, except for distortions at the surface and the interface. The same situation applies for the nitrogen level represented by the ${ }^{28} \mathrm{Si}^{14} \mathrm{~N}^{-}$signal. We also observe a decrease in one order of magnitude by RTA to an equal level as in the RTO sample. Hence, we can conclude from the TOFSIMS depth profile of the ALD- $\mathrm{SiO}_{2}$ material that (1) the as-prepared oxide is undoubtfully of a high purity with the exception for hydrogen and nitrogen residues from the APTES precursor and (2) the RTA substantially decreases the amount of hydrogen or hydrogen related moieties (such as $-\mathrm{OH})$ as well as nitrogen in the material.

RBS was measured on an $87 \mathrm{~nm}$ thick as-prepared sample (1000 ALD cycles). In Fig. 6 the RBS spectrum and

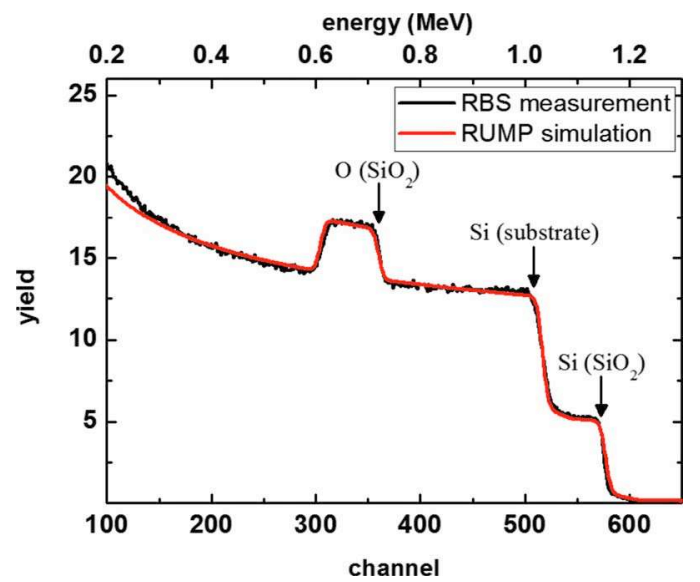

FIG. 6. (Color online) Rutherford backscattering spectrum from a $\mathrm{SiO}_{2}$ sample grown by 1000 ALD cycles. The black curve is the measurement; the red line is the fit modeled by RUMP. Best fit parameters correspond to a Si:O stoichiometry of $1: 2$ and a layer thickness of $83 \mathrm{~nm}$. No heavy impurities could be measured.

the RUMP simulation are presented. The results of the best-fit simulation are a layer composition $\mathrm{O}: \mathrm{Si}=2$ and a thickness of $(83 \pm 2) \mathrm{nm}$, i.e., in agreement with the VASE results within uncertainty. It is noteworthy to mention that in terms of RBS thickness is calculated by the measured atomic areal densities. An agreement with the thickness measured by VASE indicates a material density close to the table values for $\mathrm{SiO}_{2}$. Due to absence of any peaks beyond the silicon edge $(1.15 \mathrm{MeV})$ we can exclude heavy impurities in our material down to the ppm range.

Complementary to RBS ERDA was carried out. First of all no carbon could be detected; however, a small amount of around $(0.55 \pm 0.05)$ at. \% of nitrogen was measured for the as-prepared sample but not for the RTA sample. The origin of the $\mathrm{N}$ signal is probably the amino groups of the APTES precursor. The mechanism of nitrogen reduction by RTA is not obvious. ERDA also enabled the quantification of the hydrogen content. As depicted in Table II it is around 6.6 at. $\%$ for the as-prepared $\mathrm{ALD}-\mathrm{SiO}_{2}$ sample and more than one order of magnitude less (i.e., close to detection limit) after RTA. A simple estimation of the stoichiometry of the as-prepared material fails when only the ratio $\mathrm{O}: \mathrm{Si}$ is taken into account, as represented by $\mathrm{O}: \mathrm{Si}=2.21$ in Table II. From the FTIR and ESR data (see below) we have to assume a $\mathrm{Si}-\mathrm{O}-\mathrm{H}$ bonding configuration for the hydrogen, hence not every oxygen atom is able to bond to two silicon atoms. The last column in Table II represents the stoichiometry when the amount of hydrogen is subtracted from the oxygen prior to

TABLE II. Quantitative composition of ALD-SiO $\mathrm{S}_{2}$ from ERDA. O:Si represents the ratio of the measured oxygen to silicon concentration. Since $\mathrm{Si}-\mathrm{O}-\mathrm{H}$ configuration is expected from FTIR the ratio between the difference of oxygen and hydrogen (i.e., $\mathrm{O}-\mathrm{H}$ ) to silicon is supposed to be more representative in terms of stoichiometry. The trace amounts of nitrogen are neglected in this consideration.

\begin{tabular}{lcccccc}
\hline \hline & $\begin{array}{c}\mathrm{Si} \\
(\text { at. \% })\end{array}$ & $\begin{array}{c}\mathrm{O} \\
(\text { at. \% })\end{array}$ & $\begin{array}{c}\mathrm{N} \\
\text { (at. \%) }\end{array}$ & $\begin{array}{c}\mathrm{H} \\
\text { (at. \%) }\end{array}$ & O:Si & $(\mathrm{O}-\mathrm{H}): \mathrm{Si}$ \\
\hline As-prepared & 28.9 & 64.0 & 0.55 & 6.63 & 2.21 & 1.99 \\
RTA $\left(1000{ }^{\circ} \mathrm{C}\right)$ & 33.0 & 66.5 & 0.02 & 0.50 & 2.02 & 2.00 \\
\hline \hline
\end{tabular}



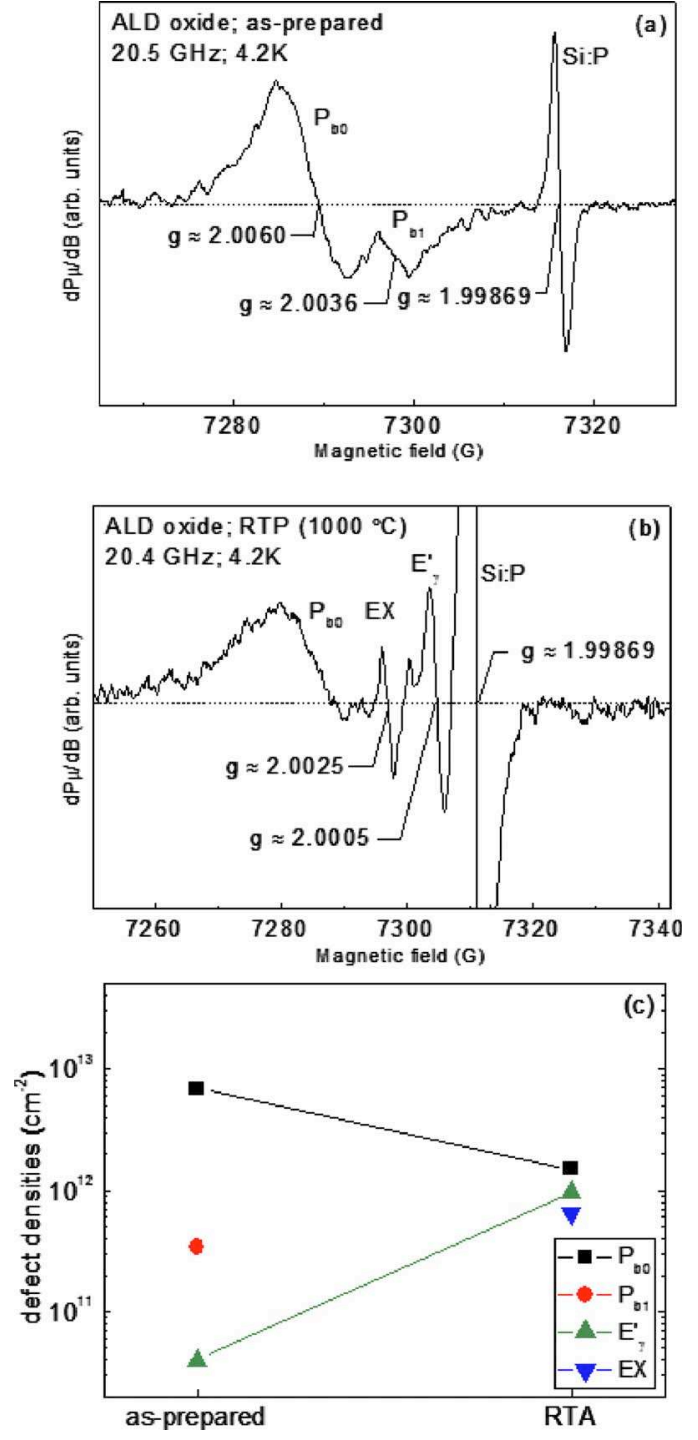

FIG. 7. (Color online) First-derivative K-band ESR spectra observed at 4.2 $\mathrm{K}$ on $\mathrm{SiO}_{2}(87 \mathrm{~nm}) /(100) \mathrm{Si}$ entities fabricated by $\mathrm{ALD} \mathrm{SiO}$ deposition (1000 cycles) (a) in the as-prepared sample for the orientation of the applied magnetic field $\mathbf{B} \| \mathbf{n}$, the (100) interface normal, and (b) after subjection to RTP $\left(1000{ }^{\circ} \mathrm{C} ; 1 \mathrm{~min} ; \mathrm{N}_{2}\right)$ followed by VUV irradiation at $300{ }^{\circ} \mathrm{C}$. The applied modulation field amplitude was $0.4 \mathrm{G}$ and the incident microwave power $\mathrm{P}_{\mu} \approx 0.3 \mathrm{nW}$. The signal at $\mathrm{g}=1.99869$ stems from a comounted Si:P marker sample, serving as g value and defect density reference. Presentation of all paramagnetic defect densities derived from the ESR spectra (c). The densities of interfacial DB defects (i.e., $\mathrm{P}_{\mathrm{b} 0}$ and $\mathrm{P}_{\mathrm{b} 1}$ ) of as-prepared ALD- $\mathrm{SiO}_{2}$ are typical for low temperature grown oxides. After RTA the $\mathrm{P}_{\mathrm{b} 0}$ defects are reduced close to the values of the standard thermal $\mathrm{Si} / \mathrm{SiO}_{2}$ interface and $\mathrm{P}_{\mathrm{b} 1}$ close to the detection limit. Insufficient $\mathrm{E}^{\prime}{ }_{\gamma}$ formation by VUV irradiation $(\sim 10 \mathrm{eV})$ for the as-prepared sample indicates the presence of $\mathrm{OH}$ groups; after RTA the $\mathrm{E}^{\prime}{ }_{\gamma}$-density adjusts close to standard values. In addition, the oxide reorganization by RTA introduces EX centers.

calculating the ratio to silicon [labeled $(\mathrm{O}-\mathrm{H}): \mathrm{Si}$ ]. Therefore, a balanced $\mathrm{O}$ to $\mathrm{Si}$ ratio is proven for $\mathrm{ALD}-\mathrm{SiO}_{2}$ before and after RTP annealing.

Occurring paramagnetic point defects were investigated by $\mathrm{K}$-band ESR at $4.2 \mathrm{~K}$ on samples prepared by $1000 \mathrm{ALD}$ cycles on p-type (100)Si substrates, resulting in a $\mathrm{SiO}_{2}$ layer of $87 \mathrm{~nm}$. Typical ESR spectra are shown in Figs. 7(a) and 7(b), the defect densities determined from the ESR measurements before and after RTA are depicted in Fig. 7(c). On the as-prepared sample [Fig. 7(a)], we observe as prominent sig- nals the anisotropic spectra from the archetypal intrinsic $\mathrm{P}_{\mathrm{b} 0}$ and $\mathrm{P}_{\mathrm{b} 1}$ interface defects, inherently generated in (100) $\mathrm{Si} / \mathrm{SiO}_{2}$ as a result of interface network/lattice mismatch, with densities inferred as $\left[\mathrm{P}_{\mathrm{b} 0}\right]=(6.9 \pm 0.3)$ $\times 10^{12} \mathrm{~cm}^{-2}$ and $\left[\mathrm{P}_{\mathrm{b} 1}\right]=(3.4 \pm 0.2) \times 10^{11} \mathrm{~cm}^{-2}$. As to $\mathrm{P}_{\mathrm{b} 0}$ centers (interfacial ${ }^{\circ} \mathrm{Si} \equiv \mathrm{Si}_{3}$ centers, where the dot represents an unpaired $\mathrm{Si} \mathrm{sp}_{3}$ hybrid), electrically identified as detrimental interface traps, ${ }^{24}$ the density is substantially larger compared with standard thermal oxide interfaces grown in the range of $850-950{ }^{\circ} \mathrm{C}$, invariably with inherent density $\approx 1 \times 10^{12} \mathrm{~cm}^{-2}$ for both $\mathrm{P}_{\mathrm{b} 0}$ and $\mathrm{P}_{\mathrm{b} 1} \cdot{ }^{25}$ Besides, no other defects could be observed, i.e., no $\mathrm{SiO}_{2}$-specific centers such as the $\mathrm{E}^{\prime}{ }_{\gamma}$ center ( $\mathrm{O}$ vacancy; generic entity ${ }^{\circ} \mathrm{Si} \equiv \mathrm{O}_{3}$ ). Subsequent vacuum ultraviolet (VUV) irradiation ( $\sim 130 \mathrm{~min})$ was found not to affect the $\mathrm{P}_{\mathrm{b}}$-type defect spectra, which may be expected in the absence of any substantial passivation of Si dangling bond (DB) defects by $\mathrm{H}$. The latter was confirmed by the observation that the $\mathrm{P}_{\mathrm{b}}$-type defect status was left unaltered after annealing the samples at $500{ }^{\circ} \mathrm{C}\left(1 \mathrm{~h}, \mathrm{~N}_{2}\right)$. However, noteworthy is that hardly any $\mathrm{E}^{\prime}{ }_{\gamma}$-centers are observable, with $\left[\mathrm{E}^{\prime}{ }_{\gamma}\right]<4.4 \times 10^{10} \mathrm{~cm}^{-2}$ (volumetric density of $\sim 5 \times 10^{15} \mathrm{~cm}^{-3}$ ), that is about 100 times less than typically observed in standard thermal oxides after such treatment $\left(\sim 4 \times 10^{17} \mathrm{~cm}^{-3}\right){ }^{26}$ For the current work, this was independently verified by growing a standard thermal (100) $\mathrm{Si} / \mathrm{SiO}_{2}$ structure with oxide thickness of $75 \pm 0.5 \mathrm{~nm}$, comparable to the $\mathrm{ALD}-\mathrm{SiO}_{2}$ layer thickness. Subjecting this layer to a similar VUV treatment resulted in a density $\left[\mathrm{E}_{\gamma}^{\prime}\right] \sim 3.3 \times 10^{12} \mathrm{~cm}^{-2}$, corresponding to a volume density of $\sim 4.4 \times 10^{17} \mathrm{~cm}^{-3}$. The likely explanation for this reduced $\mathrm{E}_{\gamma}^{\prime}$ density behavior is that the ALD oxide, a lowtemperature oxide (LTO), is an O-rich silica with substantial content of $\mathrm{Si}-\mathrm{OH}$ groups (see FTIR and ERDA section), and hence much reduced density of $\mathrm{E}^{\prime}$ precursor sites $\left(\mathrm{O}_{3}\right.$ $\equiv \mathrm{Si}-\mathrm{H}$ bonds). So, on this matter, the ALD oxide would differ from standard thermal $\mathrm{SiO}_{2}$. A noteworthy observation also is that no carbon signal could be detected: due to the utmost ESR sensitivity (i.e., ppb range) this implies amazingly the absence of any carbon residues from the metalorganic APTES precursor in agreement with the TOF-SIMS data. After RTP annealing $\left(1000{ }^{\circ} \mathrm{C}, 1 \mathrm{~min}, \mathrm{~N}_{2}\right)$ of the asprepared $\mathrm{ALD}-\mathrm{SiO}_{2}$ the ESR spectrum changes. The $\mathrm{P}_{\mathrm{b} 0}$ defect density is now found to be substantially reduced to $\left[\mathrm{P}_{\mathrm{b} 0}\right]=(1.5 \pm 0.5) \times 10^{12} \mathrm{~cm}^{-2}$, nearing the typical value (quality) for standard thermal oxide. In addition, EX centers now appear $\left([\mathrm{EX}] \sim 6.5 \times 10^{11} \mathrm{~cm}^{-2}\right)$, i.e., another $\mathrm{SiO}_{2}$-associated defect, which might be related to some kind of oxide damage introduced by the annealing as observed several times before. ${ }^{27}$ As illustrated in Fig. 7(b), after subsequent VUV treatment, we notice, besides the unaltered $\mathrm{P}_{\mathrm{b} 0}$ signal, the additional appearance of the $\mathrm{E}_{\gamma}^{\prime}$ signal now in density of $\sim 9.6 \times 10^{11} \mathrm{~cm}^{-2}$, i.e., in the same order of magnitude as in the standard thermal oxide. This result would indicate that the oxide matrix has altered, i.e., no influence of $\mathrm{OH}$ groups left after RTA. Summing up, we conclude that a reasonable $\mathrm{Si} / \mathrm{SiO}_{2}$-interface quality comparable to other low temperature grown interfaces was found in the as-prepared state, with the influential presence of $\mathrm{OH}$ groups in the oxide layer. This effect can be suppressed by RTA, where the 

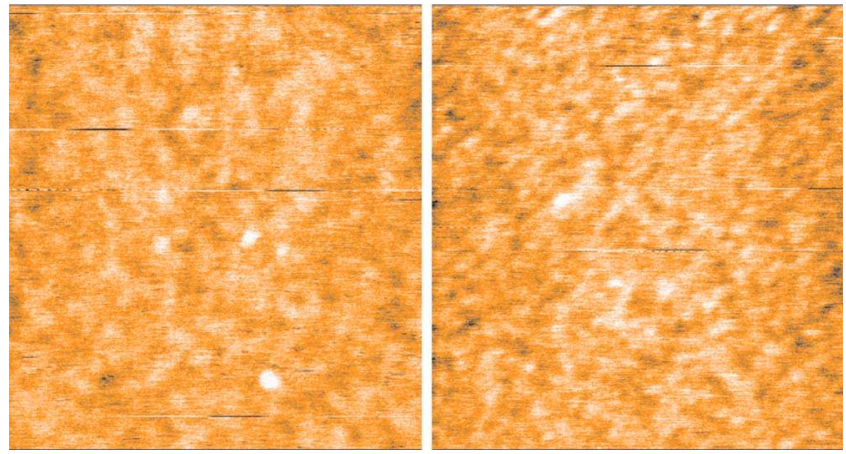

FIG. 8. (Color online) AFM topographies of as-prepared ALD-SiO 2 (left) and $\mathrm{ALD}-\mathrm{SiO}_{2}$ after RTA at $1000{ }^{\circ} \mathrm{C}$ (right). The image size is $1 \times 1 \mu \mathrm{m}^{2}$ and the height color scale is $972 \mathrm{pm}$. The AFM scans prove ideal smoothness of the material with a rms roughness of only $1.5 \AA$ (left: as-prepared) and $1.6 \AA$ (right: after RTA). No deterioration of the surface morphology by RTA is observed.

$\mathrm{Si} / \mathrm{SiO}_{2}$ structure is now taken to an improved quality, closer to that of the more standard thermal $\mathrm{Si} / \mathrm{SiO}_{2}$ entity. On ESR basis, the evidence comes from two sides: both the $\mathrm{P}_{\mathrm{b}}$-type interface defect and $\mathrm{E}_{\gamma}^{\prime}$ center densities reach close to standard values.

In order to investigate the surface roughness the ALD- $\mathrm{SiO}_{2}$ layers were measured by AFM scans. As depicted in Table I these measurements were taken on samples prepared by 1000 ALD cycles. The topography scans of the as-prepared and RTP-annealed state are presented in Fig. 8. Except for a few particles no topographical features are visible. The absence of any pinholes (with widths $\geq 20 \mathrm{~nm}$ and depths $\geq 1 \mathrm{~nm}$ ) is proven as expected for ALD growth. Furthermore, RTA does not introduce any cracks or changes in the surface morphology. Numerically, we find a root-meansquare (rms) roughness of 1.5 and $1.6 \AA$ for the as-prepared and the RTP-annealed state, respectively. Compared with bare silicon wafer roughness of about $\leq 2 \AA$ this demonstrates the ideal layer smoothness of the ALD-SiO 2 process presented here.

\section{Electrical properties}

Metal oxide semiconductor (MOS) capacitors were used to investigate the electronic properties of $\mathrm{ALD}-\mathrm{SiO}_{2}$. MOS structures were prepared on n-type silicon with aluminum contact pads (area of $0.23 \mathrm{~mm}^{2}$ ) evaporated onto the $20 \mathrm{~nm}$ thick ALD-oxide layer (200 ALD cycles). The backside aluminum contact was evaporated after removal of the backoxide layer by HF etching. Figure 9 shows the high-frequency $(1 \mathrm{MHz})$ capacitance- and conductance-voltage curves of the as-prepared and RTP-annealed samples. A cross-section TEM image is presented in the inset of Fig. 9, demonstrating the smooth surface and interface of our ALD-SiO ${ }_{2}$ layers. The bias was swept from inversion to accumulation and back (for the sake of clarity the back sweep is not shown here). The filled symbols $(\boldsymbol{\square}, \mathbf{A})$ denote measurements taken in the initial state, while curves with open symbols $(\square, \triangle)$ were measured after a bias stress in accumulation of $+10 \mathrm{~V}$ for 30 s. As can be seen here, significant differences appear between the as-prepared (Fig. 9 top) and the RTA sample (Fig. 9 bottom). From thermal oxidation it is well known that pos-

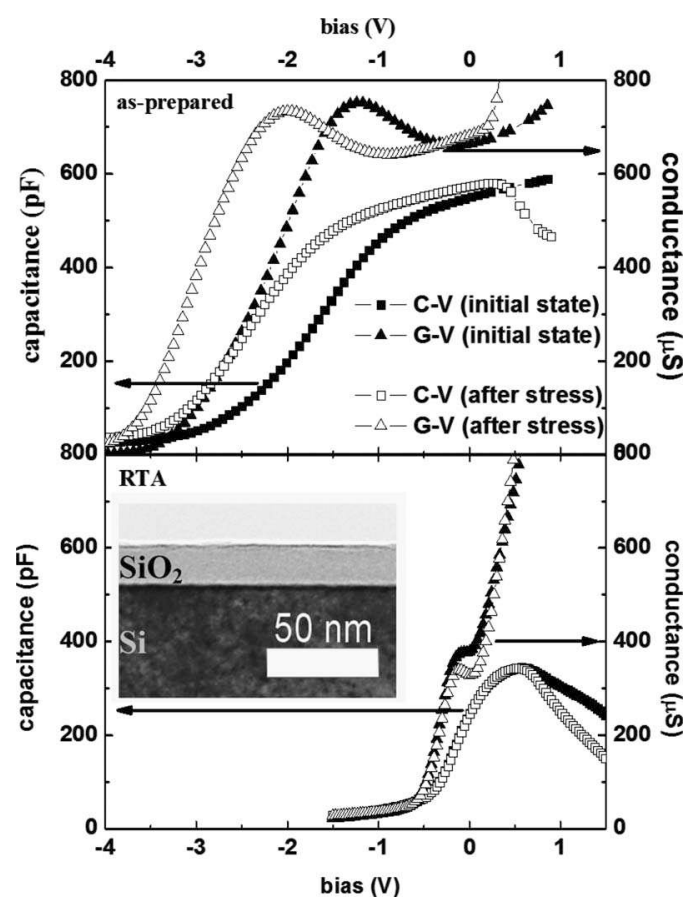

FIG. 9. High-frequency capacitance-voltage (CV) and conductance-voltage $(\mathrm{GV})$ measurements of MOS structures of as-prepared ALD-SiO ${ }_{2}$ (top) and after RTP annealing (bottom). Filled symbols $(\boldsymbol{\square}, \mathbf{A})$ represent the measurements taken in the initial state, open symbols $(\square, \triangle)$ after a bias stress in accumulation of $+10 \mathrm{~V}$ for $30 \mathrm{~s}$. Significant changes in terms of oxide capacity and flatband position occur after annealing. The inset shows a TEM cross section image of the as-prepared sample.

toxidation annealing can increase the oxide quality significantly, ${ }^{28}$ since excess silicon or oxygen atoms from silicon-rich or, respectively, oxygen-rich growth can remain in the layer after oxidation. ${ }^{29}$ Since the ALD process is based on surface chemistry rather than on mass transport it is stoichiometric, as was proven for this material previously ${ }^{7}$ and by the RBS and ERDA results presented above. To quantify the influence of thermal treatment the capacitance curves are examined first. The dielectric constant can be calculated with the help of the simple plate capacitor model using the oxide layer thickness of about $20 \mathrm{~nm}$ and the oxide capacitances in accumulation of the as-prepared sample $\left(\mathrm{C}_{\mathrm{ox}}=600 \mathrm{pF}\right)$ and the thermally treated ones $\left(\mathrm{C}_{\mathrm{ox}}=350 \mathrm{pF}\right)$. Table III summarizes the results. The dielectric constant was found to be 6.1 and 3.6 for the as-prepared state and the RTA sample, respectively. Hence, only the sample after annealing is close to the standard literature value for thermal $\mathrm{SiO}_{2}$ (approximately 3.9). The rather high value (6.1) of the dielectric constant of the as-prepared state might be attributed to additional polar-

TABLE III. Compilation of the electrical parameters derived from high frequency CV-GV measurements. Significant improvements were attained by RTA at $1000{ }^{\circ} \mathrm{C}$.

\begin{tabular}{lcc}
\hline \hline & As-prepared & RTA $\left(1000{ }^{\circ} \mathrm{C}\right)$ \\
\hline Dielectric constant $\varepsilon$ & 6.1 & 3.6 \\
Flatband voltage $\mathrm{V}_{\mathrm{FB}}(\mathrm{V})$ & -2.27 & -0.28 \\
Fixed oxide charge $\mathrm{Q}_{\mathrm{f}}\left(\mathrm{cm}^{-2}\right)$ & $+3.2 \times 10^{12}$ & $-1.9 \times 10^{10}$ \\
Trapped oxide charge $\mathrm{Q}_{\mathrm{t}}\left(\mathrm{cm}^{-2}\right)$ & $+1.0 \times 10^{12}$ & 0 \\
Interface trap level density $\mathrm{D}_{\mathrm{it}}\left(\mathrm{cm}^{-2} \mathrm{eV}^{-1}\right)$ & $1.3 \times 10^{13}$ & $1.5 \times 10^{12}$ \\
\hline
\end{tabular}


izable moieties in the layer (for instance, $-\mathrm{OH}$ ). The relationship between dielectric constant and $\mathrm{OH}$ content was demonstrated on chemical-vapor deposition (CVD) oxides before. ${ }^{30}$ The flatband capacitance method was used to investigate the behavior of oxide charges. ${ }^{31}$ Substantial changes in the flatband voltage position were observed: $\mathrm{V}_{\mathrm{FB}}=-2.27 \mathrm{~V}$ for the as-prepared sample and $-0.28 \mathrm{~V}$ for the RTA sample. By using the equation $\mathrm{V}_{\mathrm{FB}}=\mathrm{Q}_{\mathrm{f}} / \mathrm{C}_{\mathrm{ox}}$ the density of fixed oxide charge can be calculated. ${ }^{31}$ The work function difference of approximately $-0.3 \mathrm{~V}$ between the n-type silicon used here and aluminum $\left(\Phi_{\mathrm{ms}}\right)$ has to be taken into account in order to calculate $\mathrm{Q}_{\mathrm{f}}$ accurately. For the as-prepared sample a rather high value of $3.2 \times 10^{12}$ positive fixed oxide charges per $\mathrm{cm}^{2}$ (see Table III) was obtained, which is attributed to either hydroxyl groups or charges at the $\mathrm{Si} / \mathrm{SiO}_{2}$ interface. Impurities of the APTES precursor representing fixed positive charges (e.g., metals) can be ruled out, as has been proven by RBS and TOF-SIMS. Amazingly, the RTP annealing at $1000{ }^{\circ} \mathrm{C}$ reduces fixed oxide charges $\mathrm{Q}_{\mathrm{f}}$ to the $10^{10} \mathrm{~cm}^{-2}$ range, which is virtually zero within uncertainties. Comparing measurements of the initial state (Fig. 9, filled symbols $\square, \mathbf{\Lambda}$ ) and after bias stress (open symbols $\square, \triangle$ ) exhibits a severe voltage shift for the as-prepared sample, which can be attributed to trapped oxide charge $\left(\mathrm{Q}_{t}\right)$ or mobile ionic charge $\left(\mathrm{Q}_{\mathrm{m}}\right)$. Using $\Delta \mathrm{V}_{\mathrm{FB}}=\mathrm{Q} / \mathrm{C}_{\mathrm{ox}}$ we estimated $\mathrm{Q}$ to be around $10^{12} \mathrm{~cm}^{-2}$. In our case, the presence of mobile ions such as sodium has been ruled out by the ERDA data. Thus, trapped charges $Q_{t}$ must be the origin for the shift in the $\mathrm{C}-\mathrm{V}$ curve. This positive charge in the as-prepared state can be attributed to injection of carriers into the oxide. ${ }^{31}$ The RTA sample has a value of $\mathrm{Q}_{t}=0$, since within the limits of our measurement accuracy no flatband voltage shift was measured. Therefore, no significant amount of charge is trapped in the oxide under the bias stress used here $(+10 \mathrm{~V}$, $30 \mathrm{~s}$ ). Please note that extensive procedures for biastemperature stress are able to distinguish between trapped and mobile ionic charges but include stress times of up to several hours, elevated temperatures, and much stronger electrical fields. ${ }^{31}$ Our measurement indicates only a substantial improvement due to RTP annealing but cannot reveal that the oxide is absolutely free of charge traps. For the asprepared sample we have to point out that a hysteresis of several tens of millivolts on the voltage axis exists even between the up and down curves of the C-V sweep (not shown in Fig. 9 for the sake of clarity). Hence, the charges are trapped easily even under low bias in the as-prepared state.

Conductance-voltage $(\mathrm{G}-\mathrm{V})$ curves were recorded to investigate the interface properties. The interface trap level densities $\left(D_{i t}\right)$ were calculated from the peak of the corrected initial-state conductance curves according to Refs. 31 and 32. Again a rather high value of $10^{13} \mathrm{~cm}^{-2} \mathrm{eV}^{-1}$ can be calculated for the as-prepared state (Fig. 9 top). Please note that this amount of interface traps can also cause a contribution of several volts to the value of $\mathrm{V}_{\mathrm{FB}}$, hence introducing additional uncertainty about the capacitance curve of the asprepared state of our ALD-SiO ${ }_{2}{ }^{31}$ The conductance peaks are smaller and narrower for the annealed sample (Fig. 9 bottom), resulting in a value of interface trap level density $D_{i t}$ in the $10^{12} \mathrm{~cm}^{-2} \mathrm{eV}^{-1}$ range (Table III), i.e., a decrease

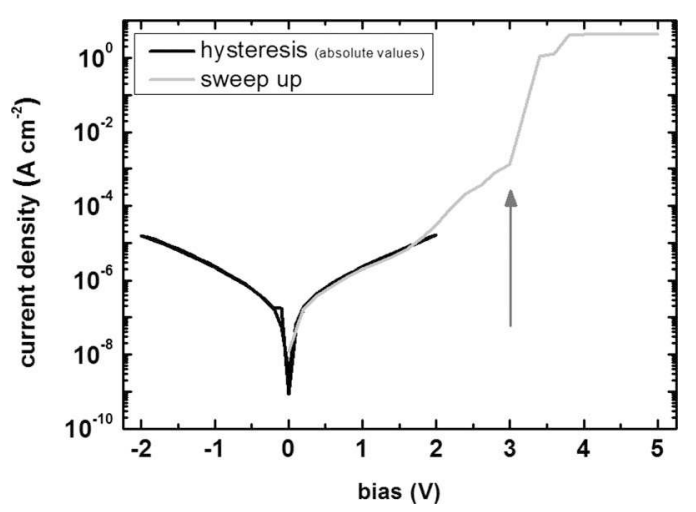

FIG. 10. Current-voltage (IV) measurements of a MOM structure with ALD-SiO ${ }_{2}$. The hysteresis curve (black) indicates reproducible electrical behavior under low electrical fields. In the sweep-up measurement (gray curve) already at $3 \mathrm{~V}$ (i.e., electrical field of $75 \mathrm{mV} / \mathrm{nm}$ ) breakdown occurs as indicated by the arrow.

by RTA of one order of magnitude but still approximately one order of magnitude too high for electronic device applications. ${ }^{8}$ However, these values are only indicative since the $\mathrm{SiO}_{2}$ deposition took place on RCA-cleaned silicon, hence on chemical oxide which is known to have poor electrical quality. The $\mathrm{D}_{\mathrm{it}}$-values obtained here are consistent with the $\mathrm{P}_{\mathrm{b}}$-type interface defects from ESR. The sudden increase in the parallel equivalent conductance accompanied by the decrease in capacitance in accumulation is another feature of Fig. 9. Since the admittance is sensitive to electrical loss the measurements are affected by further uncertainty in the capacitance measurement in accumulation, hence distorting the estimation of the oxide capacitance and the calculated dielectric constant. This circumstance could solve the apparent discrepancy between the excellent dielectric behavior measured by VASE and the 50\% too high electrically measured $\varepsilon$-value (6.1). For both samples this effect is pronounced after bias stress although the annealed sample shows this effect already in the initial state. The jump in conductance is due to the rather high conductivity of the oxide layers and in addition probably due to the creation of more conductive paths by thermal processing or bias stress.

In order to measure the current-voltage behavior a metaloxide-metal (MOM) structure was prepared by evaporation of $100 \mathrm{~nm}$ of chromium onto quartz glass, followed by the deposition of $500 \mathrm{ALD}$ cycles of $\mathrm{SiO}_{2}(\sim 40 \mathrm{~nm})$, and the subsequent structuring and evaporation of another $100 \mathrm{~nm}$ of $\mathrm{Cr}$ as top contact with $0.23 \mathrm{~mm}^{2}$. Although IV measurements could be taken with the structure in the as-prepared state, RTP annealing was not successful since cracks occurred and severe material damage was visible. Since this problem does not occur for silicon or quartz substrates it is supposed to be attributed to the chromium layer. Two IV measurements are presented in Fig. 10: a hysteresis loop (from 0 to $+2 \mathrm{~V}$, then to $-2 \mathrm{~V}$ and back to 0 ) and a bias sweep from 0 to $+5 \mathrm{~V}$. The hysteresis (due to the logarithmic scale on the ordinate the absolute values are shown) indicates reproducible IV behavior under both bias polarities, and at $1 \mathrm{~V}$ we can deduce a current density of $10^{-6} \mathrm{~A} \mathrm{~cm}^{-2}$. Hence, as mentioned above in the CV section the leakage current through the as-prepared $\mathrm{ALD}-\mathrm{SiO}_{2}$ is rather high. 
The same applies to the breakdown voltage of $3 \mathrm{~V}$ as represented by the bias sweep in Fig. 10. In the current case of an approximately $40 \mathrm{~nm}$ thick layer this corresponds to a breakthrough field of only $75 \mathrm{mV} / \mathrm{nm}$, while good thermal oxides achieve up to $1-2 \mathrm{~V} / \mathrm{nm}$. The origins of the high conductivity and weak breakdown stability as well as ways for improvement, e.g., by RTA, are an object of further investigation.

\section{CONCLUSION}

In summary, a detailed investigation of material properties of a novel low temperature thermal-ALD silicon dioxide deposition is presented. The superior aspects of this process are its low deposition temperature $\left(150{ }^{\circ} \mathrm{C}\right)$, the absence of corrosive by-products, no necessity of catalysts, and its ALD-related high degree of thickness control and perfect uniformity. The growth per cycle was determined to be 0.85 $\AA$. Many aspects of this ALD-SiO ${ }_{2}$ such as optical transmission and absorption, refractive index, stoichiometry, and chemical stability can be directly compared with thermal oxide or quartz glass already in its as-prepared state, hence representing the highest achievable material quality. Interface quality between ALD- $\mathrm{SiO}_{2}$ and $\mathrm{Si}$ substrate was shown to be comparable to other low temperature deposition methods. SIMS, ESR, RBS, and ERDA verified a high degree of purity: carbon residues can be ruled out with ppb precision and only hydrogen and about 5 atomic per mille of nitrogen could be traced. By means of ERDA the $\mathrm{H}$ content was measured to 6.6 at. \% and FTIR and ESR measurements revealed that it is bonded in a $\mathrm{Si}-\mathrm{O}-\mathrm{H}$ configuration. This probably affects certain material properties, in particular the fixed and trapped oxide charges $\left(7 \times 10^{12}\right.$ and $\left.1 \times 10^{12} \mathrm{~cm}^{-2}\right)$ or breakthrough field $(0.75 \mathrm{MV} / \mathrm{cm})$. RTA at $1000{ }^{\circ} \mathrm{C}$ was employed to investigate potential improvements. The effect was in most respects outstanding: the $\mathrm{N}$ and $\mathrm{H}$ contents as well as fixed and trapped oxide charges $\left(\mathrm{Q}_{\mathrm{f}}, \mathrm{Q}_{\mathrm{t}}\right)$ were reduced below detection limits and the interface trap level density was improved by one order of magnitude $\left(1 \times 10^{12} \mathrm{~cm}^{-2} \mathrm{eV}^{-1}\right)$. In addition, a certainty has been given that the as-prepared ALD- $-\mathrm{SiO}_{2}$ is about $10 \%$ less compact compared with the RTP-annealed state, accompanied by an improvement in BHF-etch rate to almost thermal oxide strength. Excellent surface smoothness $(1.5 \AA$ ) was demonstrated by AFM measurements and no degradation was found after RTP annealing.

The ALD- $\mathrm{SiO}_{2}$ process presented here opens new possibilities for ALD-based depositions in nanotechnology and related fields, since a conventional and well known material of reasonable quality can now be deposited easily at low temperatures and with great uniformity. Thereby it offers an attractive alternative to, e.g., the so-called LTO grown by CVD at around $425{ }^{\circ} \mathrm{C}$ or to typical plasma-enhanced chemical-vapor deposition oxides $\left(200-400{ }^{\circ} \mathrm{C}\right)$, especially when low thermal budgets, absence of plasma irradiation, and a homogeneous coverage of 3D nanostructures are essential.

\section{ACKNOWLEDGMENTS}

The authors gratefully acknowledge the financial support by DFG under Project No. Za191/14-3 and by the German Ministry of Education and Research (BMBF Grant No. 03N8701). K. P. Meyer is acknowledged for technical support. R. Schmidt-Grund and M. Grundmann are acknowledged for support in ellipsometry.

${ }^{1}$ M. Knez, K. Nielsch, and L. Niinistö, Adv. Mater. (Weinheim, Ger.) 19, 3425 (2007).

${ }^{2}$ S. W. Lee, K. Park, B. Han, S. H. Son, S. K. Rha, C. O. Park, and W. J. Lee, Electrochem. Solid-State Lett. 11, G23 (2008).

${ }^{3}$ J. D. Ferguson, E. R. Smith, A. W. Weimer, and S. M. George, J. Electrochem. Soc. 151, G528 (2004).

${ }^{4}$ B. A. McCool and W. J. DeSisto, Chem. Vap. Deposition 10, 190 (2004).

${ }^{5}$ J. W. Klaus, O. Sneh, and S. M. George, Science 278, 1934 (1997).

${ }^{6}$ J. W. Lim, S. J. Yun, and J. H. Lee, ETRI J. 27, 118 (2005).

${ }^{7}$ J. Bachmann, R. Zierold, Y. T. Chong, R. Hauert, C. Sturm, R. SchmidtGrund, B. Rheinländer, M. Grundmann, U. Gösele, and K. Nielsch, Angew. Chem., Int. Ed. 47, 6177 (2008).

${ }^{8}$ G. D. Wilk, R. M. Wallace, and J. M. Anthony, J. Appl. Phys. 89, 5243 (2001).

${ }^{9}$ J. Robertson, Rep. Prog. Phys. 69, 327 (2006).

${ }^{10}$ M. M. Frank, Y. J. Chabal, M. L. Green, A. Delabie, B. Brijs, G. D. Wilk, M. Y. Ho, E. B. O. da Rosa, I. J. R. Baumvol, and F. C. Stedile, Appl. Phys. Lett. 83, 740 (2003).

${ }^{11}$ M. L. Green, M. Y. Ho, B. Busch, G. D. Wilk, T. Sorsch, T. Conard, B. Brijs, W. Vandervorst, R. I. Räisänen, D. Muller, M. Bude, and J. Grazul, J. Appl. Phys. 92, 7168 (2002).

${ }^{12}$ R. B. Marcus and T. T. Sheng, J. Electrochem. Soc. 129, 1278 (1982).

${ }^{13}$ Y. H. Cho, S. W. Lee, B. J. Kim, and T. Fujii, Nanotechnology 18, 465303 (2007).

${ }^{14}$ N. Kaji, Y. Tezuka, Y. Takamura, M. Ueda, T. Nishimoto, H. Nakanishi, Y. Horiike, and Y. Baba, Anal. Chem. 76, 15 (2004).

${ }^{15}$ A. Burns, H. Ow, and U. Wiesner, Chem. Soc. Rev. 35, 1028 (2006).

${ }^{16}$ K. Pitzschel, J. M. M. Moreno, J. Escrig, O. Albrecht, K. Nielsch, and J. Bachmann, ACS Nano 3, 3463 (2009).

${ }^{17}$ L. Moreno i Codinachs, C. Birkenstock, T. Garma, R. Zierold, J. Bachmann, K. Nielsch, M. J. Schöning, and A. Fontcuberta i Morral, Phys. Status Solidi A 206, 435 (2009).

${ }^{18}$ N. P. Barradas, C. Jeynes, and R. P. Webb, Appl. Phys. Lett. 71, 291 (1997).

${ }^{19}$ M. A. Stevens Kalceff and M. R. Phillips, Phys. Rev. B 52, 5 (1995).

${ }^{20}$ Handbook of Optical Constants of Solids, edited by E. D. Palik (Academic, New York, 1997).

${ }^{21}$ V. Gottschalch, R. Schmidt, B. Rheinländer, D. Pudis, S. Hardt, J. Kvietkova, G. Wagner, and R. Franzheld, Thin Solid Films 416, 224 (2002).

${ }^{22}$ V. P. Tolstoy, I. V. Chernyshova, and V. A. Skryshevsky, Handbook of Infrared Spectroscopy of Ultrathin Films (Wiley, New York, 2003); M. Zacharias, D. Dimora-Malinovska, and M. Stutzmann, Philos. Mag. B 73, 799 (1996)

${ }^{23}$ M. Perego, S. Ferrari, S. Spiga, E. Bonera, M. Fanciulli, and V. Soncini, Appl. Phys. Lett. 82, 121 (2003).

${ }^{24}$ E. H. Poindexter, G. J. Gerardi, M.-E. Rueckel, P. J. Caplan, N. M. Johnson, and D. K. Biegelsen, J. Appl. Phys. 56, 2844 (1984); A. Stesmans and V. V. Afanas'ev, Phys. Rev. B 57, 10030 (1998).

${ }^{25}$ A. Stesmans and V. V. Afanas'ev, J. Vac. Sci. Technol. B 16, 3108 (1998).

${ }^{26}$ P. G. Tello, V. V. Afanas'ev, and A. Stesmans, Microelectron. Eng. 72, 81 (2004); A. Stesmans and V. V. Afanas'ev, J. Appl. Phys. 97, 033510 (2005).

${ }^{27}$ W. E. Carlos and S. M. Prokes, J. Appl. Phys. 78, 2129 (1995); H. J. von Bardeleben, J. L. Cantin, J. J. Ganem, and I. Trimaille, in Defects in High- $\kappa$ Gate Dielectric Stacks, NATO Science Series II, edited by E. Gusev (Kluwer, Dordrecht, 2006); B. B. Triplett, P. T. Chen, Y. Nishi, P. H. Kasai, J. J. Chambers, and L. Colombo, J. Appl. Phys. 101, 013703 (2007). 
${ }^{28}$ B. J. O’Sullivan, P. K. Hurley, C. Leveugle, and J. H. Das, J. Appl. Phys. 89, 3811 (2001).

${ }^{29}$ A. Ludsteck, J. Schulze, I. Eisele, W. Dietl, and Z. Nenyei, J. Appl. Phys. 95, 2827 (2004).
${ }^{30}$ B. Fowler and E. O'Brian, J. Vac. Sci. Technol. B 12, 441 (1994).

${ }^{31}$ E. H. Nicollian and J. R. Brews, MOS (Metal Oxide Semiconductor) Physics and Technology (Wiley, New York, 1982).

${ }^{32}$ J. R. Brews, Solid-State Electron. 26, 711 (1983). 